\title{
Neuropsychological dysfunction related to earlier occupational exposure to mercury vapor
}

E.C. Zachi', D.F. Ventura ${ }^{1}$, M.A.M. Faria ${ }^{2}$ and A. Taub ${ }^{3}$

\author{
'Instituto de Psicologia e Núcleo de Neurociências e Comportamento, \\ 2Departamento de Medicina Legal, Ética Médica e Medicina Social e do Trabalho, \\ ${ }^{3}$ Departamento de Psiquiatria, Faculdade de Medicina, Universidade de São Paulo, \\ São Paulo, SP, Brasil
}

\section{Correspondence \\ E.C. Zachi \\ Instituto de Psicologia, USP \\ Av. Prof. Mello Moraes, 1721 \\ Bloco A, Sala D-09 \\ 05508-900 São Paulo, SP \\ Brasil \\ E-mail: elainez@usp.br}

Presented at the Symposium on Sensory and Neuropsychological Losses Due to Mercury Intoxication and to Other Neurodegenerative

Processes. Studies in Humans and in Animal Models. Águas de Lindóia, SP, Brazil, August 25-29, 2004.

Research supported by CAPES/ PROCAD (No. 0019/01-1), CNPq (No. 55.1639/2002-4), and FAPESP (Temático 02/12733-8) to D.F. Ventura. E.C. Zachi was the recipient of a Master's fellowship from FAPESP (No. 03/03427-3) and D.F. Ventura was the recipient of a CNPq research fellowship.

Received March 6, 2006 Accepted January 19, 2007

\section{Abstract}

We assessed the neuropsychological test performances of 26 patients (mean age $=41.5 \pm 6.1$ years; mean years of education $=9.8 \pm 1.8 ; 20$ males) diagnosed with chronic occupational mercurialism who were former workers at a fluorescent lamp factory. They had been exposed to elemental mercury for an average of $10.2 \pm 3.8$ years and had been away from this work for $6 \pm 4.7$ years. Mean urinary mercury concentrations 1 year after cessation of work were $1.8 \pm 0.9 \mu \mathrm{g} / \mathrm{g}$ creatinine. Twenty control subjects matched for age, gender, and education (18 males) were used for comparison. Neuropsychological assessment included attention, inhibitory control, verbal and visual memory, verbal fluency, manual dexterity, visual-spatial function, executive function, and semantic knowledge tests. The Beck Depression Inventory and the State and Trait Inventory were used to assess depression and anxiety symptoms, respectively. The raw score for the group exposed to mercury indicated slower information processing speed, inferior performance in psychomotor speed, verbal spontaneous recall memory, and manual dexterity of the dominant hand and non-dominant hand $(\mathrm{P}<0.05)$. In addition, the patients showed increased depression and anxiety symptoms $(\mathrm{P}<0.001)$. A statistically significant correlation (Pearson) was demonstrable between mean urinary mercury and anxiety trait $(\mathrm{r}=0.75, \mathrm{P}=0.03)$. The neuropsychological performances of the former workers suggest that occupational exposure to elemental mercury has long-term effects on information processing and psychomotor function, with increased depression and anxiety also possibly reflecting the psychosocial context.

\section{Introduction}

The nervous system is considered to be the main organ affected by elemental mercury vapor (1-4), with accumulation in the nervous cells appearing to persist throughout life (5). Nevertheless, mercury continues
Key words

- Mercury, occupational exposure

- Cognitive assessment

- Neuropsychological

dysfunction

- Neuropsychological tests
..... 
$\mathrm{Hg}^{3+}$ ) vapor (6) during work, such as motor impairment, salivation, insomnia, memory losses, gingivitis (5), and erethism (7), which consists of changes of personality and behavior such as excitability and excessive shyness (8). It is a central nervous system syndrome (9) involving sensory losses that affect visual function (10-12), emotional disturbances (13) and personality changes including irritability, agitation, mood lability, shyness, and depression (5,8,14-16). Symptoms of mercurialism can be found in individuals with a history of chronic exposure to mercury vapor years after the exposure has ceased. In this case, urinary mercury levels will show normal values because urine excretion of large volumes of mercury occurs only during and shortly after exposure $(5,7)$.

A number of studies have shown that cognitive dysfunctions develop in individuals exposed to mercury vapor. Some studies with industry workers currently exposed to mercury vapor have found deficits in shortterm memory $(17,18)$, mental arithmetic, switching attention, and reaction time (19), psychomotor function $(19,20)$, logic memory, and manual dexterity (21). However, not all studies find changes in the same parameters $(13,22,23)$ and this disagreement could not be explained by the exposure levels (23). Among the effects of mercury intoxication, motor impairment is apparently the most consistently reported symptom $(9,23)$.

Neuropsychological evaluation was performed in most studies of intoxicated patients during the period of exposure to elemental mercury. Only a few have shown results of assessments after the cessation of the chronic exposure to mercury vapor $(14,15,24-27)$. Some of these studies did not find significant differences between exposed and controls in any of the cognitive or motor functions assessed $(25,27)$ while others have suggested that neuronal dysfunction is likely to be persistent even years after the end of chronic exposure $(5,7,8,14,15,26)$. The likelihood of reversibility of the neuropsycho- logical deficit is therefore controversial.

The purpose of the present study was to determine if there are long-term effects of exposure to elemental mercury vapor on cognitive and motor functions, as well as symptoms of depression and anxiety.

\section{Material and Methods}

\section{Participants}

Thirty-four former workers at a fluorescent lamp plant were recruited from the outpatient population (total mercury-intoxicated patients available $=44$ ) of the Hospital das Clínicas (HC), Faculdade de Medicina, Universidade de São Paulo (FMUSP), São Paulo, SP, Brazil, where they had been treated. They had been exposed to elemental mercury vapor for 4 to 20 years $(10.2 \pm 3.8$ years) and the period after cessation of exposure ranged from 1 to 18 years $(6 \pm 4.7$ years). They were away from work because of health problems related to chronic occupational mercurialism and, in some cases, due to repetitive work. The inclusion criterion was a diagnosis of chronic occupational mercurialism and exclusion criteria were history of alcoholism, drug abuse, cerebrovascular or endocrine disease, head injury, or chelation treatment. The diagnosis of mercurialism was based on clinical examination, neurological evaluation, exposure history, and increased levels of mercury in urine during the time of exposure.

Control individuals (18 males and 2 females) were recruited and selected among the staff of the University of São Paulo where this study was conducted. A history of alcoholism, drug abuse, cerebrovascular, or endocrine disease, head injury, and acute or chronic exposure to mercury were the exclusion criteria. Thirty-two employees were recruited, 6 of whom were excluded because they were under 30 years of age (exposed participants ranged in age from 33 to 54 years), 2 reported endocrine disease, 1 had 
an epileptic episode history, and 3 refused to participate. The demographic characteristics of the participants are summarized in Table 1.

No significant differences were found between the two groups regarding age or years of formal education.

Urinary mercury samples were analyzed by cold vapor atomic absorption spectrophotometry. Metal concentrations were determined using a calibration curve consisting of 5 standards. In order to ensure accurate measurements, the calibration curves were checked by the Levey-Jennings method (28) as a quality control procedure. The data on urinary elemental mercury levels $(\mathrm{U}-\mathrm{Hg}$; $\mu \mathrm{g} / \mathrm{g}$ creatinine, $\mathrm{Cr}$ ) were collected from the medical records of HC-USP. The urinary mercury levels during exposure were available for only 18 patients $(46.8 \pm 22.1 \mu \mathrm{g} / \mathrm{g}$ $\mathrm{Cr})$. However, a high urinary mercury concentration could be estimated for the whole group because the former workers came from the same lamp production line.

Mercurialism can be found in individuals with normal U-Hg because the kidneys eliminate large volumes of mercury only during and shortly after the period of exposure $(5,7)$. The mean U-Hg concentrations in the exposed group were normal 1 year after removal from exposure $(1.8 \pm 0.8 \mu \mathrm{g} / \mathrm{g} \mathrm{Cr})$. Thirteen patients were diagnosed with tendinitis (affecting one or both arms) related to repetitive work in manufacturing lamps. Twenty of them were taking medication for the treatment of depression and/or anxiety (Table 2).

\section{Procedures}

Each participant underwent neuropsychological assessment during a session of about $1.5 \mathrm{~h}$ of duration, which included a brief clinical interview and neuropsychological testing. The anamnesis included questions concerning the subjects' demographic data, job history, life-style habits, and clinical data. The patients were also asked about their occupational histories at the fluorescent lamp plant.

The neuropsychological battery included tests of attention, short term memory, and mental control (WMS Digit Span subtest) (29), inhibitory control (Stroop Interference

Table 1. Demographic characteristics of subjects exposed to mercury.

\begin{tabular}{|c|c|c|c|c|c|c|}
\hline & \multicolumn{3}{|c|}{ Exposed group $(\mathrm{N}=26)$} & \multicolumn{3}{|c|}{ Control group $(\mathrm{N}=20)$} \\
\hline & $\mathrm{N}(\%) \mathrm{N}$ & Mean \pm SD & Median & $\mathrm{N}(\%) \mathrm{N}$ & Mean \pm SD & Median \\
\hline Age (years) & & $41.5 \pm 6.1$ & 41.5 & & $42.7 \pm 8.2$ & 42 \\
\hline Educational level (years & & $9.8 \pm 1.8$ & 9.5 & & $9.8 \pm 2.2$ & 11 \\
\hline \multicolumn{7}{|l|}{ Gender } \\
\hline Male & $20(77 \%)$ & - & - & $18(90 \%)$ & - & - \\
\hline Female & $6(23 \%)$ & - & - & $2(10 \%)$ & - & - \\
\hline \multicolumn{7}{|l|}{ Work } \\
\hline Employed & $0(0 \%)$ & - & - & $20(100 \%$ & \%) - & - \\
\hline $\begin{array}{l}\text { Away from work due } \\
\text { to mercury intoxicatior }\end{array}$ & $26(100 \%$ & $\%) \quad-$ & - & $0(0 \%)$ & - & - \\
\hline \multicolumn{7}{|l|}{ Alcohol consumption } \\
\hline Drinkers & $14(54 \%)$ & - & - & $15(75 \%)$ & - & - \\
\hline Non-drinkers & $12(46 \%)$ & - & - & $5(25 \%)$ & - & - \\
\hline \multicolumn{7}{|l|}{ Smokers } \\
\hline Current & $2(8 \%)$ & - & - & $4(20 \%)$ & - & - \\
\hline Ex-smokers & $2(8 \%)$ & - & - & $0(0 \%)$ & - & - \\
\hline Non-smokers & $22(84 \%)$ & - & - & $16(80 \%)$ & - & - \\
\hline
\end{tabular}

Data are reported as number of subjects with percent in parentheses, mean $\pm S D$, and median. There were no statistical differences between groups in terms of age and education (independent $t$-test).

Table 2. Data related to the 26 mercury-exposed participants.

\begin{tabular}{|c|c|c|c|}
\hline & $\mathrm{N}(\%)$ & Mean \pm SD & Range \\
\hline Duration of exposure (years) & - & $10.2 \pm 3.8$ & $4-33$ \\
\hline $\begin{array}{l}\text { Period since removal from } \\
\text { exposure (years) }\end{array}$ & - & $6 \pm 4.7$ & $1-18$ \\
\hline $\begin{array}{l}\mathrm{U}-\mathrm{Hg} \text { during the period of } \\
\text { exposure }(\mu \mathrm{g} / \mathrm{g} \mathrm{Cr})\end{array}$ & $18(70 \%)$ & $46.8 \pm 22.1$ & $20-73.8$ \\
\hline $\begin{array}{l}\mathrm{U}-\mathrm{Hg} 1 \text { year after cessation } \\
\text { of exposure }(\mu \mathrm{g} / \mathrm{g} \mathrm{Cr})\end{array}$ & - & $1.8 \pm 0.9$ & $0.8-2.8$ \\
\hline Tendinitis diagnosis & $13(50 \%)$ & - & - \\
\hline \multicolumn{4}{|l|}{ Psychoactive medication } \\
\hline $\begin{array}{l}\text { Antidepressants (tricyclics or } \\
\text { serotonin reuptake inhibitors) }\end{array}$ & $5(19 \%)$ & - & - \\
\hline Tranquilizers (benzodiazepines) & $5(19 \%)$ & - & - \\
\hline Combined & $6(23 \%)$ & - & - \\
\hline None & $10(39 \%)$ & - & - \\
\hline
\end{tabular}

Data are reported as number of subjects with percent in parentheses, mean $\pm \mathrm{SD}$, and range. $\mathrm{U}-\mathrm{Hg}=$ urinary mercury levels; $\mathrm{Cr}=$ creatinine. 
Test) (30), verbal memory (Buschke Selective Reminding Test, SRT) (30), visual memory (WMS Visual Reproduction subtest) (29), manual dexterity (Grooved Pegboard; Lafayette Instrument), verbal fluency (FAS) (30), visuomotor ability (WAIS-R Block Design subtest) (31), executive function (Wisconsin Card Sorting Test) (32), and verbal knowledge (WAIS-R Vocabulary subtest) (31). After this neuropsychological assessment the subjects were instructed to complete the Beck Depression Inventory (BDI) (33) and the State-Trait Anxiety Inventory (STAI) (34).

The study was approved by the Ethics Committee of the Psychology Institute, University of São Paulo, and all subjects gave written informed consent prior to testing.

\section{Statistical analysis}

Data with non-normal distribution (years of education, cognitive and motor tests, and mood inventory scores) were log-transformed to achieve normalization. Independent $t$-tests were applied to the continuous demographic variables (age and years of education) to assess differences between groups.

Group comparisons were made using the general linear model, which combines analysis of variance and regression procedures and allows the assessment of continuous and categorical variables (covariates/confounders) simultaneously. Dependent variables were the test scores. Assessment of potential confounding variables was taken into account. Age, raw score in the Vocabulary test as a measure of pre-morbid general ability, and drinking habits are potential confounders frequently considered in neuropsychological studies. BDI scores were also used as covariates because depression is reported to compromise cognitive functions $(35,36)$. Since anxiety showed a high correlation with depression, STAI scores were not considered in order to avoid redundancies. Since antidepressants (tricyclic and serotonin reuptake inhibitors) and tranquilizers (benzodiazepines) can impair cognitive and/or psychomotor skills $(37,38)$, the use (yes/no) of one or both medications was included in the analysis. A diagnosis of tendinitis (yes/no) was considered to be a potential confounder in the assessment of the tests that require manual motor performances (Visual Reproduction, Grooved Pegboard, and Block Design).

Pearson's correlation coefficients were calculated to detect possible associations between exposure to mercury variables (urine $\mathrm{Hg}^{0}$ levels, duration of exposure and the time since the cessation of exposure) and neuropsychological performance within the exposed group.

Statistical analyses were performed using the MINITAB 14.0 software (39).

\section{Results}

The group exposed to mercury had significantly different scores compared to the control group on variables related to the SRT, Stroop Test, and Grooved Pegboard after accounting for potential confounders $(\mathrm{P}<0.05)$. The medians and ranges of the score tests, F-ratios, and $\mathrm{P}$ values are reported in Table 3. The exposed participants a) took a longer mean time in naming colors in the Stroop Test parts $1(\mathrm{P}=0.03)$ and $2(\mathrm{P}$ $=0.01)$, but not in part $3(\mathrm{P}=0.09), \mathrm{b})$ showed lower scores for verbal memory on the SRT long-term recall $(\mathrm{P}=0.03)$, longterm storage $(\mathrm{P}=0.00)$, consistent long-term recall $(\mathrm{P}=0.01)$, and delayed recall $(\mathrm{P}=$ $0.00), \mathrm{c})$ showed longer mean times in manual dexterity with the dominant hand $(\mathrm{P}=0.00)$ and the non-dominant hand $(\mathrm{P}=0.00)$ in the Grooved Pegboard test. Exposed participants also had higher scores in the depression (BDI) and anxiety (STAI) inventories (P = 0.00; Figure 1).

A salient feature was the profile of the exposed group within the tests. Compared 
with the control group, the former workers showed poorer results in the Stroop Test parts 1 and 2, that mainly require information processing and psychomotor speed, but not in part 3, a measure of inhibitory control. Indeed, their low SRT scores in long-term recall and consistent long-term recall suggest impairment of primary verbal memory spontaneous recall. In contrast, the cued recall scores were not statistically different between groups, indicating the integrity of verbal memory storage ability in the exposed group, but a difficulty in spontaneously recalling the stored words. Although the groups differed significantly in longterm storage, this sub-item only reflects the sum of words recalled in two consecutive trials without being reminded during testing.

The associations between the exposure indicators and the patient's neuropsychological performances calculated by Pearson correlation coefficients are presented in Table 4. The urinary mercury concentration measured 1 year after the end of exposure was significantly correlated only with the STAI score $(r=0.75 ; \mathrm{P}=0.03)$. The concentrations of mercury in urine at the time of exposure, duration of exposure and the period of removal from exposure were not correlated with any test or inventory score (Table 4).

\section{Discussion}

The present study focused on determining if neuropsychological and motor impairment could be detected in a group of workers formerly employed by a fluorescent lamp plant. They had been away from the source of exposure for an average of 6 years ( 1 to 18 years) and had a diagnosis of chronic occupational mercurialism.

The exposed subjects showed reduced performance in specific neuropsychological functions and motor skills. There were slowed information processing speeds (Stroop test parts 1 and 2) and impairment in verbal memory (SRT), hand-eye coordination, and manual dexterity (Grooved Pegboard). We also found symptoms of depression (BDI) and anxiety (STAI) in these patients. When analyzing the verbal memory performance of the exposed subjects it is important to emphasize that although they failed long-

Table 3. Comparison of test scores between subjects exposed to mercury and controls.

\begin{tabular}{|c|c|c|c|c|}
\hline \multirow[t]{2}{*}{ Tests } & \multicolumn{2}{|c|}{ Exposed group } & \multicolumn{2}{|c|}{ Control group } \\
\hline & Median & Range & Median & Range \\
\hline \multicolumn{5}{|l|}{ Digit span } \\
\hline Forward & 5 & $1-9$ & 6 & $3-9$ \\
\hline Backward & 4 & $0-9$ & 4 & $2-6$ \\
\hline \multicolumn{5}{|l|}{ Stroop (time in s) } \\
\hline Part 1 & $17^{*}$ & $13-55$ & 14 & $9-27$ \\
\hline Part 2 & $22.5^{*}$ & $14-82$ & 17 & $11-42$ \\
\hline Part 3 & 32.5 & $19-69$ & 29 & $16-56$ \\
\hline \multicolumn{5}{|l|}{ SRT } \\
\hline Total number of words & 88 & $40-124$ & 107 & $44-126$ \\
\hline Long-term recall & $63^{*}$ & $5-119$ & 89.5 & $22-122$ \\
\hline Long-term storage & $86^{*}$ & $9-125$ & 103 & $6-130$ \\
\hline Consistent long-term recall & $34^{*}$ & $0-96$ & 64 & $10-130$ \\
\hline Random long-term recall & 30 & $5-57$ & 25.5 & $9-60$ \\
\hline Delayed recall & $8^{*}$ & $2-12$ & 9 & $6-12$ \\
\hline Cued recall & 11 & $4-12$ & 12 & $9-12$ \\
\hline Intrusions & 2 & $0-14$ & 0.5 & $0-8$ \\
\hline \multicolumn{5}{|l|}{ Visual reproduction } \\
\hline Immediate recall & 24 & $6-40$ & 26 & $8-34$ \\
\hline Delayed recall & 17.5 & $1-39$ & 22.5 & $2-31$ \\
\hline \multicolumn{5}{|l|}{ FAS } \\
\hline $\mathrm{F}$ & 10 & $1-19$ & 11 & $6-18$ \\
\hline A & 7.5 & $2-18$ & 11 & $7-16$ \\
\hline S & 7 & $1-16$ & 9 & $3-15$ \\
\hline Total & 25 & $2-50$ & 32.5 & $20-49$ \\
\hline \multicolumn{5}{|l|}{ Grooved pegboard (time in s) } \\
\hline Dominant hand & $79^{*}$ & $69-130$ & 75.5 & $46-99$ \\
\hline Non-dominant hand & $95^{*}$ & $76-177$ & 82.5 & $60-120$ \\
\hline Block design & 20 & $3-38$ & 22 & $3-43$ \\
\hline \multicolumn{5}{|l|}{ Wisconsin } \\
\hline Errors & 66 & $14-97$ & 52.5 & $11-97$ \\
\hline Perseverative errors & 36 & $8-96$ & 23 & $5-94$ \\
\hline Completed categories & 2 & $0-6$ & 4 & $0-6$ \\
\hline Vocabulary & 28 & $20-39$ & 33 & $10-53$ \\
\hline
\end{tabular}


Figure 1. Box plots representing the performances (median, first and third quartiles, and 95 and 95 percentiles) of exposed and control participants on the Beck Depression Inventory (BDI) and State-Trait Anxiety Inventory (STAI) $(\mathrm{P}=0.00)$. U-Hg = urinary mercury levels. $\mathrm{P}<0.05$ compared to control (independent $t$-test). term and delayed recall, they performed in the normal range in cued recall, suggesting a deficit in spontaneous recall. Our hypothesis is that the poor results of verbal learning

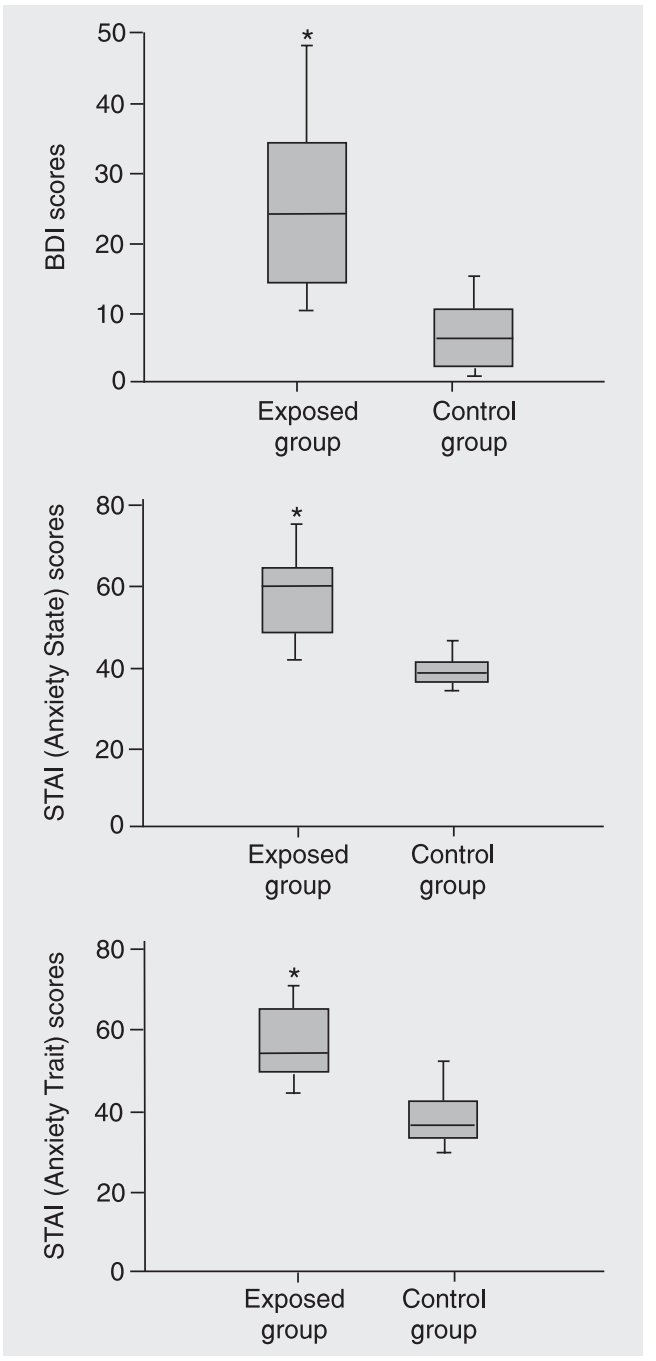

Table 4. Pearson correlation coefficients between exposure variables and tests and inventory scores among former workers.

\begin{tabular}{llcc}
\hline Variable & Domain & $r$ & $P$ \\
\hline Duration of exposure & All tests and inventories & - & \\
Period since removal from exposure & All tests and inventories & - & \\
U-Hg during the period of exposure & All tests and inventories & - & \\
U-Hg 1 year after removal of exposure & Anxiety trait (STAl) & 0.75 & 0.03 \\
& Other tests and inventories & - &
\end{tabular}

$\mathrm{U}-\mathrm{Hg}=$ urinary mercury levels. See Procedures in Material and Methods. -, no correlation. ability are related to information processing deficit. High BDI and STAI scores were expected, since depression and anxiety are symptoms of chronic mercurialism. Nevertheless, the possibility that these symptoms are associated with psychosocial problems related to being unemployed could not be ruled out. In this case, depression and anxiety would represent a reaction to the psychosocial context.

Few investigations have focused on the question of cognitive impairment association with past exposure to mercury vapor $(14,15,24-27)$. Our findings in terms of preserved functions were consistent with previous studies that failed to detect impairment of immediate memory (24-27), vocabulary (24-26), and viso-spatial ability $(14,15,24)$.

Our results agree with the slowed information processing speed (test of color card reading) and motor deficits found in exminers $(\mathrm{U}-\mathrm{Hg}=3.2 \pm 4.1 \mathrm{ng} / \mathrm{g})$ who were previously exposed to high levels of mercury vapor for 15.5 years on average $(\mathrm{SD}=$ 8.7) $(14,15)$. However, we did not detect visuo-spatial or short-term memory deficits. A possible explanation is the fact that the previous study examined ex-miners of a mercury mine 18 years after the end of exposure and certainly included individuals who were older and had been exposed to higher mercury vapor concentrations than in the present study. Indeed, a correlation was observed between the number of years after the cessation of exposure and better performance in the short-memory test (Digit Span) (15).

Mathiesen et al. (24) also found motor, psychomotor, visuomotor, and attention deficits in former workers of a chloralkali plant (mean U-Hg = $1.8 \pm 1.3 \mathrm{nmol} / \mathrm{mmol} \mathrm{Cr}$ ) who had been exposed to mercury vapor for $7.9 \pm$ 6.8 years (time since the end of exposure $=$ $12.7 \pm 11.7$ years). In contrast to our results, scores in a visual memory ability test were also decreased, particularly in individuals with high cumulative exposure levels ( $\mathrm{U}-\mathrm{Hg}$ $\geq 3000 \mathrm{nmol} / \mathrm{L}$ ). On the other hand, Bast- 
Pettersen et al. (27) did not find visual memory impairment in former chloralkali workers (mean U-Hg $=1.65 \mathrm{nmol} / \mathrm{mmol} \mathrm{Cr}$, range $0.2-5.2 \mathrm{nmol} / \mathrm{mmol} \mathrm{Cr}$ ) exposed to mercury for 13.1 years on average (range 2.8-34.5) and removed from exposure for 4.8 years (range 4.2-10.0). The majority of these participants had been examined during the period of exposure in a previous study (22) that reported impairment of immediate visual memory, suggesting recovery of function.

Our findings of verbal memory impairment support previous studies that showed a significantly worse performance in a list learning test (26) and in a word pair test (individuals with the highest intensity of exposure showed a deficit) (24) in former employees of a chloralkali plant. In contrast, Letz et al. (25) did not detect statistical differences in verbal memory between former workers of a heavy industrial plant and controls. However, these discordant findings may reflect the time since the cessation of exposure (30 years or more).

Motor dysfunction associated with a history of past exposure to mercury vapor has been well described. In the present study, there was a significant difference between exposed participants and controls in the Grooved Pegboard test that required manual dexterity and hand-eye coordination. Indeed, the general linear model analysis was done considering a diagnosis of tendinitis to be a confounder, and this variable was not significantly associated with motor performance. Previous studies conducted after the cessation of exposure to mercury detected impairment of motor coordination $(14,15)$, manual dexterity $(14,15,24,26)$, and reaction time $(14,15,24)$. Letz et al. (25) reported a significant association between hand-eye coordination and cumulative mercury exposure in former workers examined 30 years after the end of exposure.

The present study found no association between the impairment detected in the pa- tients and duration of exposure to mercury or length of the period away from exposure. Because of the variability among the workers' job categories in the plant, the degree of exposure was also variable, and therefore the failure to detect significant relationships is not surprising. Similarly, urinary mercury levels during the time of exposure were not observed to be associated with any test or inventory score. It is possible that effects of $\mathrm{U}-\mathrm{Hg}$ on cognitive and motor functions were not detected because of the small sample size. However, urinary mercury concentration measured 1 year after the end of exposure correlated positively with the anxiety trait (STAI). Mercury intoxication has been reported to provoke changes in personality traits as a symptom of erethism $(3,13)$. Alterations have been reported even at very low exposure concentrations, such as higher trait anxiety scores in women exposed to elemental mercury from dental amalgams compared to women with no dental fillings, attributed to a possible dysfunctional norepinephrine metabolism (40).

The limitations of the present investigation are mainly related to the demographic characteristics of the groups studied. A larger sample size might have helped detect other possible cognitive dysfunctions related to mercury exposure. Another problem is the variable duration of exposure and time after the end of exposure. Indeed, there were changes in type of occupation during employment, with different mercury vapor levels in the air in different occupations.

Former workers of a fluorescent lamp plant manifested slowed information processing and impaired psychomotor performance many years after cessation of exposure, showing that there might be persistent damage in neurobehavioral functions due to long-term exposure to mercury. The mood disturbances observed are expected in individuals with chronic occupational mercurialism but may also reflect psychosocial problems. Further longitudinal work on this sam- 
ple is recommended to confirm whether or not the neuropsychological and motor deficits observed persist for many years.

\section{Acknowledgments}

\author{
Appreciation is expressed to Marcelo
}

Fernandes Costa, Ph.D. (Universidade de São Paulo), for critical discussions of this work and for methodological support during the study. We are also grateful to the neuropsychologist Shirley S. Lacerda (Hospital Albert Einstein) for assistance with data discussion and interpretation.

\section{References}

1. Echeverria D, Aposhian HV, Woods JS, Heyer NJ, Aposhian MM, Bittner AC Jr, et al. Neurobehavioral effects from exposure to dental amalgam $\mathrm{Hg}(0)$ : new distinctions between recent exposure and $\mathrm{Hg}$ body burden. FASEB J 1998; 12: 971-980.

2. Anonymous. Mercury toxicity. Agency for toxic substance and disease registry. Am Fam Physician 1992; 46: 1731-1741.

3. Langworth S, Almkvist O, Soderman E, Wikstrom BO. Effects of occupational exposure to mercury vapour on the central nervous system. Br J Ind Med 1992; 49: 545-555.

4. Vassallo DV, Massaroni L, Oliveira EM, Rossoni LV, do Amaral SM, Vassallo PF. Acute toxic actions of mercury on the cardiovascular system. Arq Bras Cardiol 1996; 67: 39-45.

5. Faria MA. Chronic occupational metallic mercurialism. Rev Saúde Pública 2003; 37: 116-127.

6. Azevedo FA. Toxicologia do mercúrio. São Paulo: InterTox; 2003.

7. Rodriguez ZC, Rodriguez JEL. Metallic mercury intoxication. Bol Asoc Med P R 1982; 74: 380-382.

8. Satoh $\mathrm{H}$. Occupational and environmental toxicology of mercury and its compounds. Ind Health 2000; 38: 153-164.

9. Langolf GD, Chaffin DB, Henderson R, Whittle HP. Evaluation of workers exposed to elemental mercury using quantitative tests of tremor and neuromuscular functions. Am Ind Hyg Assoc J 1978; 39: 976-984.

10. Ventura DF, Simões AL, Tomaz S, Costa MF, Lago M, Costa MTV, et al. Color vision and contrast sensitivity losses of mercury intoxicated industry workers in Brazil. Environ Toxicol Pharmacol 2005; 19: 523-529.

11. Ventura DF, Costa MT, Costa MF, Berezovsky A, Salomao SR, Simoes AL, et al. Multifocal and full-field electroretinogram changes associated with color-vision loss in mercury vapor exposure. Vis Neurosci 2004; 21: 421-429.

12. Gobba F, Cavalleri A. Evolution of color vision loss induced by occupational exposure to chemicals. Neurotoxicology 2000; 21: 777-781.

13. Hua MS, Huang CC, Yang YJ. Chronic elemental mercury intoxication: neuropsychological follow-up case study. Brain Inj 1996; 10 : 377-384.

14. Kishi R, Doi R, Fukuchi $Y$, Satoh $H$, Satoh $T$, Ono A, et al. Subjective symptoms and neurobehavioral performances of ex-mercury miners at an average of 18 years after the cessation of chronic exposure to mercury vapor. Mercury Workers Study Group. Environ Res 1993; 62: 289-302.

15. Kishi R, Doi R, Fukuchi $Y$, Satoh $H$, Satoh $T$, Ono A, et al. Residual neurobehavioural effects associated with chronic exposure to mercury vapour. Occup Environ Med 1994; 51: 35-41.

16. O'Carroll RE, Masterton G, Dougall N, Ebmeier KP, Goodwin GM. The neuropsychiatric sequelae of mercury poisoning. The Mad
Hatter's disease revisited. Br J Psychiatry 1995; 167: 95-98.

17. Smith PJ, Langolf GD, Goldberg J. Effect of occupational exposure to elemental mercury on short term memory. Br J Ind Med 1983; 40: 413-419.

18. Soleo L, Urbano ML, Petrera V, Ambrosi L. Effects of low exposure to inorganic mercury on psychological performance. $\mathrm{Br} J$ Ind Med 1990; 47: 105-109.

19. Liang YX, Sun RK, Sun Y, Chen ZQ, Li LH. Psychological effects of low exposure to mercury vapor: application of a computer-administered neurobehavioral evaluation system. Environ Res 1993; 60: 320-327.

20. Lucchini R, Calza S, Camerino D, Carta P, Decarli A, Parrinello G, et al. Application of a latent variable model for a multicenter study on early effects due to mercury exposure. Neurotoxicology 2003; 24: 605-616.

21. Piikivi L, Hanninen H, Martelin T, Mantere P. Psychological performance and long-term exposure to mercury vapors. Scand $J$ Work Environ Health 1984; 10: 35-41.

22. Ellingsen DG, Bast-Pettersen R, Efskind J, Thomassen Y. Neuropsychological effects of low mercury vapor exposure in chloralkali workers. Neurotoxicology 2001; 22: 249-258.

23. Meyer-Baron M, Schaeper M, Seeber A. A meta-analysis for neurobehavioural results due to occupational mercury exposure. Arch Toxicol 2002; 76: 127-136.

24. Mathiesen T, Ellingsen DG, Kjuus H. Neuropsychological effects associated with exposure to mercury vapor among former chloralkali workers. Scand J Work Environ Health 1999; 25: 342-350.

25. Letz R, Gerr F, Cragle D, Green RC, Watkins J, Fidler AT. Residual neurologic deficits 30 years after occupational exposure to elemental mercury. Neurotoxicology 2000; 21: 459-474.

26. Frumkin H, Letz R, Williams PL, Gerr F, Pierce M, Sanders A, et al. Health effects of long-term mercury exposure among chloralkali plant workers. Am J Ind Med 2001; 39: 1-18.

27. Bast-Pettersen R, Ellingsen DG, Efskind J, Jordskogen R, Thomassen $Y$. A neurobehavioral study of chloralkali workers after the cessation of exposure to mercury vapor. Neurotoxicology 2005; 26: 427-437.

28. Levey S, Jennings ER. The use of control charts in the clinical laboratory. Am J Clin Pathol 1950; 20: 1059-1066.

29. Wechsler D. Wechsler Memory Scale Revised - User's manual. San Antonio: The Psychological Corporation; 1987.

30. Spreen O, Strauss E. A compendium of neuropsychological tests. New York: Oxford University Press; 1991.

31. Wechsler D. Wechsler Adult Inteligence Scale Revised - User's manual. New York: Psychological Corporation; 1981.

32. Heaton RK, Chelune GJ, Talley JL, Kay GG, Curtis G. Wisconsin Card Sorting Test (WCST) - Manual revised and expanded. Odessa: 
Psychological Assessment Resources; 1993.

33. Cunha JA. Escalas Beck - manual. São Paulo: Casa do Psicólogo; 2001.

34. Biaggio AMB, Natalício L. Inventário de ansiedade traço-estado manual. Rio de Janeiro: CEPA; 1979.

35. Antikainen R, Hanninen T, Honkalampi K, Hintikka J, KoivumaaHonkanen $\mathrm{H}$, Tanskanen $\mathrm{A}$, et al. Mood improvement reduces memory complaints in depressed patients. Eur Arch Psychiatry Clin Neurosci 2001; 251: 6-11.

36. Fossati P, Coyette F, Ergis AM, Allilaire JF. Influence of age and executive functioning on verbal memory of inpatients with depres- sion. J Affect Disord 2002; 68: 261-271.

37. McKim WA. Drugs and behavior. 4th edn. New Jersey: Prentice Hall; 2000.

38. Stewart SA. The effects of benzodiazepines on cognition. J Clin Psychiatry 2005; 66 (Suppl 2): 9-13.

39. Minitab statistical software for Windows. [Computer program]. Version 14.0. Pennsylvania: Minitab Inc.; 2003.

40. Siblerud RL, Motl J, Kienholz E. Psychometric evidence that mercury from silver dental fillings may be an etiological factor in depression, excessive anger, and anxiety. Psychol Rep 1994; 74: 67-80. 